\title{
Promoting behavior-related low back health in nursing staff by in-person and interactive social media interventions in the workplace: a randomized trial
}

Seyedeh Somayeh Kazemi ( $\nabla$ somayehkazemi@modares.ac.ir)

Tarbiat Modares University Faculty of Medical Sciences https://orcid.org/0000-0001-9650-4569

\section{Sedigheh-Sadat Tavafian}

Tarbiat Modares University Faculty of Medical Sciences

\section{Claire E Hiller}

The University of Sydney School of Medicine

\section{Alireza Hidarnia}

Tarbiat Modares University Faculty of Medical Sciences

\section{Ali Montazeri}

Iranian Institute for Health Sciences Research

\section{Research article}

Keywords: PRECEDE-PROCEED model, in-person intervention, social media intervention, low back pain, promoting behavior, nurse

Posted Date: January 13th, 2020

DOI: https://doi.org/10.21203/rs.2.20573/v1

License: (c) (i) This work is licensed under a Creative Commons Attribution 4.0 International License.

Read Full License 


\section{Abstract}

Background: Nurses are put at high risk of work-related low back pain (LBP) due to the nature of their work. There is wide scientific evidence that the incidence and prevalence of LBP in nurses is high. Therefore, promoting behaviors for low back health in nurses is essential. The aim of this study was to develop and evaluate a theory-based educational intervention on promoting behaviors of low back health via in-person and social media education among nursing personnel with LBP.

Methods: The educational content was developed with six modules: knowledge, attitude, self-efficacy, reinforcing factors, enabling factors and behavior. Evaluation of the content was undertaken in nurses, mean age $36.50 \pm 5.79$ years, with LBP recruited to a community randomized controlled trial with two modes of delivery: in-person $(n=60)$ and social media $(n=60)$. Data were collected with a self-designed questionnaire at baseline, 3 and 6 months. Baseline comparisons between groups were made with MannWhitney U Test for non-normal data and T-Test for normal data. Comparison of change scores between groups and two delivery types across the three time periods used the mixed between-within subject analysis of variance.

Results: A total of 120 nurses received the allocated intervention and completed the baseline and followup questionnaires. The results indicated there were no significant statistical differences between two delivery types in the variables at the baseline $(p>.05)$. All educational component scores increased at 3months in both groups. At the 6-month follow-up scores increased for enabling factors and behavior in the in-person group, while in the social media group all scores increased except for attitude. Based on Bonferroni Post hoc analysis there was the difference between the delivery types; social media was more effective in knowledge $(p=.01)$, self-efficacy $(p=.03)$, reinforcing factor $(p=.05)$ and behavior $(p=.001)$ than the in-person intervention.

Conclusion: An educational program for low back health was developed based on the PRECEDEPROCEED model and proved effective at improving knowledge, attitude, self-efficacy, reinforcing factors, enabling factors and behavior. However, delivery via social media was more successful than in-person in the maintenance of behavior over the long-term.

\section{Background}

The nurse is one of the key members of the health care team who has the appropriate scientific and practical capability for nursing care at different levels of prevention [1]. The American Nurses Association considers nurses' roles are to maintain the health of different body systems, to collaborate and coordinate with other therapeutic systems, and to carry out criteria and statutory activities, taking into account the health of the community [2]. Nurses account for more than $70 \%$ of health workers [3] in which various roles are played, such as caring, support, protection, coordination, and training roles [4]. Due to the nature of their work nurses routinely execute activities that require lifting heavy loads, lifting patients, working in awkward postures, and transferring patients out of bed and from the floor [5]. These 
work tasks put nurses at high risk of work-related musculoskeletal disorders (WMSDs) such as low back pain (LBP) [6]. There is wide scientific evidence that incidence and prevalence of LBP are very high and it is the leading cause of sickness absence in healthcare workers, especially nurses working in hospitals [7, 8], due to exposure to ergonomic and other risk factors [7, 9]. Therefore, promoting behaviors of low back health in nurses is essential.

Health promoting behaviors is an international priority and a major challenge for health care providers in recent decades [10]. Although studies have shown that ergonomic education to maintain an appropriate body posture at the workplace can reduce the prevalence of low back pain among nurses [11], few studies have focused on changing risk behaviors, such as not maintaining a correct posture. Further, few have based their research on interventional models or theories, and few have focused on the course of low back pain after an intervention [11-13].

The PRECEDE-PROCEED Model, which has been a cornerstone of health promotion practice for more than three decades, can help to guide the process of designing, implementing, and evaluating health behavior change programs [14]. Its use leads to planning interventions that are specifically targeted to these desired outcomes. This model can determine the causes of performing or not performing health behaviors. As well, the PRECEDE-PROCEED model determines the reinforcing and enabling factors in performing and maintaining health behavior [15]. Indeed, according to the PRECEDE-PROCEED model, three categories of factors change behavior: predisposing factors, reinforcing factors, and enabling factors [14]. Each of these factors will have different effects on behavior, but a combination of these is needed to change behavior [14]. In other words, factors that affect participation in health-promoting behaviors include those that are internal or intrinsic to the individual and those that are environmental or extrinsic $[16,17]$. Intrinsic factors that influence whether one engages in health-promoting activities include personal characteristics, knowledge, attitude, value, and self-efficacy. Extrinsic factors include situational and interpersonal influences, reinforcing factors such as social relationship, reward, and satisfaction from adopting the behavior, enabling factors such as managers' support, existence and utilization of resources. [14].

Based on the existing literature [18-21] and interviews with nurses about LBP experience, factors affecting LBP health behaviors in the workplace [22] and appropriate education methods in the work place, an educational intervention was designed and developed. The aim of this study was to develop and evaluate a theory-based educational intervention (PRECEDE-PROCEED Model) on promoting behaviors of low back health via in-person and social media education among nursing personnel with LBP.

\section{Methods}

\section{Study design}


This was a community randomized-control trial. The Tarbiat Modares University of Medical Sciences approved the study protocol. Written informed consent was obtained from all participants.

\section{Participants}

The study was conducted in two hospitals affiliated to Mazandaran University of Medical Sciences in Sari, Iran with a similar level of healthcare complexity. The participants were female nurses. To recruit participants, an information session was held at each hospital, informed consent obtained and each participant nurse completed the baseline questionnaires. Follow-up questionnaires were administered three and six months after the intervention. The questionnaires were anonymous.

\section{Inclusion and exclusion criteria}

Inclusion criteria for the study were: having self-reported work-related low back pain which was examined by a specialist in occupational medicine, at least one year of nursing work experience, have access and skill to use a mobile phone and internet. Exclusion criteria were: having an illness, being pregnant.

\section{Intervention}

\section{Development of the educational program}

The main aim of the program was promoting behavior related to low back health. So we found out what factors promoted health behaviors and what factors prevented health behaviors in the workplace. Thus, based on the educational/ecological diagnosis and administrative/policy diagnosis phases of the PRECEDE model, we carried out interviews with nursing personnel. First, based on the educational/ecological diagnosis phase, we identified predisposing, enabling, and reinforcing factors [14] via an interview with nurses $(n=18)$, educational supervisors $(n=3)$, hospital manager $(n=1)$, and head nurse $(n=4)$. Indeed, they are factors that if modified, will most likely result in behavior change, as well as sustain it $[14,23)$. Predisposing factors are those characteristics that motivate any recommended behavior before or during the happening that behavior [14]. Predisposing factors include an individual's knowledge, beliefs, values, and attitudes. Enabling factors are those characteristics that facilitate action and include programs, services, availability and accessibility of resources, or new skills required to enable behavior change [14]. Reinforcing factors are rewards or punishments following a consequence of any recommended behavior [14]. They could strengthen the motivation and some of the reinforcing factors include social support, peer support, or similar.

Then in the administrative/policy diagnosis phase [24], we investigated appropriate strategies for education implementation through interviews with the hospital managers, head nurses, nursing managers, and educational supervisors about hospital policies. This phase focused on the administrative and organizational concerns that must be addressed prior to program implementation. This included assessment of resources, development and allocation of budgets, looking at organizational barriers, and coordination of the program with other departments, including external organizations and the community [24]. 
Eventually, according to the results obtained from interviews and a literature review [18-21], the educational intervention was designed and developed. The educational intervention included knowledge, attitude, self-efficacy, reinforcing and enabling factors for health-promoting behavior of the low back.

The educational content included: work-related low back pain, individual and occupational factors of low back pain, ergonomic and correct position of the spine in daily work, the necessity to prevent back pain and maintain lower back health, low back health promotion behaviors, principles of low back pain prevention, and promoting self-efficacy for adaptation with an ergonomic posture. In addition, the importance of colleagues was explored for improving the health behaviors of low back pain, reinforcing factors in health promotion behaviors, enabling factors which included programs, services, availability and accessibility of resources, or new skills required to enable behavior change, and stress management.

Before the education implementation, the website and educational content were evaluated by an educational technology expert, health education expert, educational management expert, and nurses. Educational material was evidence-based and used comprehensible language and diversity of formats, including PowerPoint, photos, educational videos, and 3D animation.

\section{Validation of the educational program}

The educational program was validated as part of a larger randomized controlled trial. The CONSORT statement and the extension for randomized trials were used to describe the design of the study $[25,26]$.

\section{Implementation of educational program}

Participants in intervention hospital 1, received the educational content in two 60 minute sessions, and through lectures, role-playing, questions and responses, and discussing nurse's comments and experiences. Participants at intervention hospital 2, received the educational content by interactive social media. For each participant in group 2, a proprietary username and password were created and instructions for social media log on and use were given. The content of the education was uploaded to the site on two days and at a specified time. Nurses could download and save the educational content, film, and animation. Since the website was interactive, nurses could write their questions and comments on the website and receive feedback from the researcher. Also, participants were given a mobile number to contact the researcher if they had any problems, such as logging into the website or installing the app.

\section{Outcome}

The study outcome was promoting behavior related to low back health.

\section{Instrument}

A self-designed questionnaire (Occupational Back Pain Prevention Behavior Questionnaire) was an instrument for measuring the constructs of the PRECEDE-PROCEED Model such as educational/ecological diagnosis (predisposing, reinforcing and enabling factors) and administrative/policy diagnosis (educational strategies). This questionnaire consisted of 30 items and six components of health status including knowledge (4-item), attitude (5-item), self-efficacy (6-item), 
reinforcing factor (5-item), enabling factor (7-item), and behavior (3-item). To calculate each subscale or total score for the Occupational Back Pain Prevention Behavior Questionnaire first we added raw scores and linearly transferred it to a score from 0 to 100. Items were scored with the Likert spectrum. The Likert scale is a five-point scale from 1 to 5 . The greater the score the better condition in nurses. Validity and reliability of this questionnaire were confirmed by Cronbach's alpha of 0.92 [27]. The questionnaire was completed at baseline, 3-month and 6-month follow-up. The questionnaire took 15 to 20 min to complete.

\section{Sample size}

The sample size was calculated at $95 \%$ confidence level and $80 \%$ power and with a mean difference and standard deviation of 5.44 (2.55) before and after the intervention, 55 were considered in each hospital [28] and with $10 \%$ chance of dropout, 60 nurses were estimated to be required in each hospital.

\section{Randomization}

Hospitals were allocated to the intervention group 1 and the intervention group 2 by draw. Then nursing staffs with low back pain at each hospital were selected by simple randomization. Each hospital sent a list of nurses' IDs to the study coordinator. The coordinator coded the IDs to number 1-300. A random number table using these numbers was generated. The coordinator contacted the nurses in order of the random table, and then assessed them for eligibility and consent. This process continued until the sample size of 60 was reached.

This study was single blind trial and the participants did unaware of the intervention they receive. To ensure allocation concealment, randomization to groups was undertaken by a blinded remote investigator not involved in recruitment.

\section{Statistical analysis}

The Shapiro-Wilk test was used to determine the normality of the data. To compare baseline scores of knowledge, attitude, self-efficacy, reinforcing factors, enabling factors and behavior, Mann-Whitney U Test was used for non-normal data and a T-Test for normal data. We planned to use a mixed-between-within subject analysis for each factor, but as they were not all normally distributed, so change scores were calculated. To compare change scores of the six components between groups over time and also to compare the two types of delivery, a mixed between-within subject analysis of variance was conducted with post-hoc Bonferroni analysis on significant results. Additionally, Pearson-correlation was used to determine the relationship between self-efficacy and behavior. All analysis was with SPSS IBM Statistics version 23.

\section{Results}

An educational intervention was developed based on six components: knowledge, attitude, self-efficacy, reinforcing factors, enabling factors and behavior. It was modified for an in-person and social media delivery. Validation was undertaken with 120 female nurses (mean age $36.50 \pm 5.79$ years, mean height $161.93 \pm 6.68 \mathrm{~cm}$, mean weight $66.08 \pm 11.65 \mathrm{~kg}$ and mean BMI $25.08 \pm 3.21$, Table 1). Figure 1 displays 
the flowchart and overview of the trial study. There were no significant differences between the two groups at baseline in any of the six components (Table 2).

Table 3 displays the six components of the educational intervention over the 3 and 6-month follow-up in both of groups (Figure 2). Based on calculated change scores, all components increased over the 3months after intervention in both groups. But over the 6-month follow-up increased scores for enabling factors and behavior occurred in the in-person group, while in the social media all components except for attitude improved (Table 4). Based on Bonferroni Post hoc analysis there was a difference between the delivery types; social media was more effective and successful in knowledge $(p=.01)$, self-efficacy $(p=$ $.03)$, reinforcing factor $(p=.05)$ and behavior $(p=.001)$ than the in-person delivery. There was a positive moderate correlation between self-efficacy and behavior, $r=.540, p \leq .0001$.

\section{Discussion}

An educational program based on the PRECEDE-PROCEED model for promoting behavior related to low back health was successfully developed and implemented via two methods, in-person and social media. Evaluation of the program showed that all components improved over the 3-month follow-up for both delivery types and over the 6-month follow-up for the social media intervention, while two components improved over the 6-month follow-up for the in-person intervention (enabling factors and behavior).

Our educational program was in line with previous literature, which acknowledged that the use of community-based participatory research models to guide intervention development can contribute to more engaging and effective health behavior interventions [29-32]. A fundamental assumption of the PRECEDE-PROCEED model is the active participation of its intended audience, that is that the participants will take an active part in defining their own problems, establishing their goals and developing their solutions [14]. This is supported by a systematic review which advocated for the use of social or behavioral theories in the prevention of musculoskeletal injuries [33]. Steinmetz et al., showed interventions based on the Theory of Planned Behavior on average, were successful in changing variables such as attitude and behavior [34]. The results of Ebadifard' et al's., study indicated the effectiveness of an in-person educational intervention based on a PRECEDE-PROCEED model combined with self-management theory improved self-care behaviors in patients [35].

In our study, nurses' knowledge and attitude towards LBP increased over the 3-month period for both interventions. Nurses are knowledgeable regarding health-promoting activities such as physical activity, stress management, and maintaining healthy relationships. However, this knowledge may not translate into nurses' own self-care or health behavior [36]. Our result was supported by Janssens' study which showed an increase in knowledge and attitude of the care staff following a healthcare program [37]. As well as, this finding supported through other studies. In these studies, improved knowledge and attitude (pain management, self-care, lifestyle, mental health, oral health) was achieved following educational intervention delivered by in-person and web-based [37-43]. Similarly the result of McNamara' study et al., showed the acute pain educational program intervention improved nurses' knowledge and attitudes 
towards pain assessment and management over the 6 weeks [44]. At the 6-month follow-up, nurses' knowledge and attitude in the in-person and attitude in the social media group was reduced. Schaller et al. compared two educational methods in physical activity (movement coaching; phone and web and lowintensity control; using two oral presentations). They found that at 6-month follow-up there were no statistically significant between-group differences in physical activity [45]. It seems face-to-face education or a booklet is not sufficient for enhancement of knowledge. There is a need to use an educational method can be used at any time and place and a social media delivery can be more effective in the long-term.

The educational program led to increasing self-efficacy over 3-months. maintenance at 6 months was more effective with the program being delivered via social media. In a study by George et al, the findings suggested the use of two types of in-person education (Dedicated Education Unit and Traditional Clinical Education) had a significant increase in self-efficacy scores post clinical education in both groups [46]. Also Thompson' study support the effect of social media intervention to improve self-efficacy. Thompson showed that the online intervention in nursing students were associated with a statistically significant increase in self-efficacy on bullying behavior [47]. At 6-months follow-up, self-efficacy decreased among the in-person group. It seems that using a program with easy access will help to maintain self-efficacy. However, in-person group did not have access to educational materials after the intervention ended.

In our study, there was a moderate positive correlation between self-efficacy and behavior. Higher selfefficacy score indicated increased health behavior. These results were supported by Fida' study et al, who found self-efficacy was an important protective factor against negative behavior in the workplace [48]. Self-efficacy can potentiate an effect on learning new behavior. Indeed, self-efficacy is defined as one's perceived capability for learning or performing actions at designed levels [49]. Self-efficacy is hypothesized to influence behaviors and environments and in turn be affected by them $[49,50]$. People with higher levels of self-efficacy tend to choose more challenging tasks, persist in personal behaviors when encountering difficulties, confront adversities with courage, and have higher levels of confidence [51]. Self-efficacy is extensively applied in health behavior-related fields, on patients suffering from chronic pain, and workplace incivility and burnout in nursing $[48,52]$. A systematic review demonstrates that interventions that modify attitudes, norms, and self-efficacy are effective in promoting health behavior change [53]. Likewise self-efficacy can enhance self-care behavior in patients [54].

Irvine demonstrated that a theoretically based stand-alone mobile-web intervention that tailors content to users' preferences and interests can be an effective tool in self-management of low back pain and health behavior [55]. Zachary' study discovered the effect of an E-learning module in addition to attitudes, confidence and knowledge, on clinical skills chronic low back pain in older adults [56].

Nursing leaders can be concerned with improving participation in health-promoting behaviors not only because it is a workplace health issue, but because it is potentially a financial and patient safety issue. Fortunately, we saw an increase in the enabling factors over the 3 and 6 months' follow-up in both of groups. This suggests that management factors and hospital policies can play a major role in the 
adoption and promotion of health behaviors. Leaders and managers can provide the environment for exercise facilities and comfortable spaces for managing workplace stress. Ross' study supports the results of our study. The results provided strategies in the nursing workplace to improve the health of staff nurses by increasing health-promoting behaviors [36]. The social relationship between colleagues, reward, and satisfaction from the outcome of adopting the behavior, and the role of colleagues are effective factors in improving health behaviors. The effect of these factors has observed over the 3months follow-up in both groups. But over the 6-months follow-up decreased in the in-person group. We provided the certification to participate in the intervention as a reward. After the intervention, we encouraged participants to maintain the behavior through the website and recalled the role of colleagues in promoting the behavior. Perhaps because of the lack of interaction at the end of in-person education, the role of the reinforcing factors was diminished and individuals had not acted as incentives for one another.

The result showed behavior score was improved over 3-month after the intervention. This is in line with the findings of Maghbouli et al., from the effect of an educational intervention in healthy behaviors of the nursing students to prevent LBP [57]. Even a qualitative study also noted interactive websites for people with chronic pain lead to improved health literacy, self-efficacy, empowerment, improvements in physical exercise and overall quality of life [58]. However, in our study the social media intervention was more successful in improving behavior than in-person intervention over the 6-month follow-up. Literature showed the mobile-web program (FitBack) in adults performed better on behavior of self-management of low back pain, and worksite outcomes at 4-month follow-up. Further, indicated greater improvement at 4month follow-up on patient activation, constructs of the theory of planned behavior, and attitudes toward pain [46].

\section{Limitations}

In the in-person group, we were not sure that nurses performed health behaviors in the workplace. But in the social media group, we were aware through nurses' feedback on the website. The study participants were female nurses. Educational intervention for male nurses is also recommended in the next studies.

\section{Conclusion}

Nurses' knowledge of the importance of health-behaviors regarding LBP does not mean they apply healthy behaviors to themselves. The theory-based educational intervention for LBP proved effective at improving knowledge, attitude, self-efficacy, reinforcing factors, enabling factors and behavior immediately and after 3 months. However, social media was more successful than the in-person in the maintenance of behavior over the long-time (6-months). Changing health-behaviors need suitable context and access to education through the best and easiest channels, which appears interactive social media to be appropriate.

\section{Declarations}




\section{Ethics approval and consent to participate}

The Ethics Committee of Tarbiat Modares University approved the study. Written informed consent was obtained from all individual participants included in the study. Participants were ensured that their name and information would be kept confidential and they were told that they were free to leave the study if they did not wish to do so.

\section{Consent to publication}

Not applicable.

\section{Availability of data and materials}

Data are contained within the manuscript. The datasets used and/or analyzed during the current study is supplements.

\section{Competing interests}

The authors declare that they have no competing interests.

\section{Funding}

None.

\section{Authors' Contributions}

SSK was the main investigator and collected and analyzed the data, and wrote the first draft. $\mathrm{CH}$ contributed to drafting, editing, and interpretation of data. SST supervised the study. AH was the study advisor. AM performed was the study advisor, the analysis and edited the manuscript. All authors read and approved the final manuscript.

\section{Acknowledgements}

This paper was originated from the first investigator's Ph.D. thesis at Department of Health Education and Promotion, Faculty of Medical Sciences, Tarbiat Modares University, Tehran, Iran. The authors thank the staff of hospitals of Mazandaran University of Medical Sciences. In particular nurses, head nurses, educational supervisors, nursing managers, and hospital managers.

\section{References}


1. Heidary A, Mazlom R, Ildarabadi E. Nursing's position in health care delivery system in Iran. 2012.

2. Allamzadeh M. A study on the knowledge of employed nurses in psychiatry unit of hospitals affiliated to Tehran University of Medical sciences about their professional roles: Dissertation) Tehran: Iran university of Medical Sciences; 1992.

3. Marcum J, Ridenour M, Shaff G, Hammons M, Taylor M. A study of professional nurses' perceptions of patient education. The journal of continuing education in nursing. 2002;33(3):112-8.

4. Potter PA, Perry AG. Fundamentals of nursing. 2004.

5. Ando S, Ono Y, Shimaoka M, Hiruta S, Hattori Y, Hori F, et al. Associations of self estimated workloads with musculoskeletal symptoms among hospital nurses. Occupational and environmental medicine. 2000;57(3):211-.

6. Feyer A-M, Herbison P, Williamson AM, de Silva I, Mandryk J, Hendrie L, et al. The role of physical and psychological factors in occupational low back pain: a prospective cohort study. Occupational and environmental medicine. 2000;57(2):116-20.

7. Serra C, Soler-Font M, García AM, Peña P, Vargas-Prada S, Ramada JM. Prevention and management of musculoskeletal pain in nursing staff by a multifaceted intervention in the workplace: design of a cluster randomized controlled trial with effectiveness, process and economic evaluation (INTEVAL_Spain). BMC Public Health. 2019;19(1):348.

8. Vargas-Prada S, Serra C, Martínez JM, Ntani G, Delclos GL, Palmer KT, et al. Psychological and culturally-influenced risk factors for the incidence and persistence of low back pain and associated disability in Spanish workers: findings from the CUPID study. Occup Environ Med. 2013;70(1):57-62.

9. Vargas-Prada Figueroa S, Martínez JM, Coggon D, Delclòs i Clanchet J, Benavides FG, Serra C. Health beliefs, low mood, and somatizing tendency: contribution to incidence and persistence of musculoskeletal pain with and without reported disability. Scandinavian Journal of Work, Environment and Health 2013; 39 (6): 589-598. 2013.

10. Myers RE. Promoting healthy behaviors: how do we get the message across? International journal of nursing studies. 2010;47(4):500-12.

11. Julia Smedley F, Trevelyan F, Inskip H, Buckle P, Cooper C. Impact of ergonomic intervention on back pain among nurses. Scand J Work Environ Health. 2003;29(2):117-23.

12. Sheikhzadeh A, Gore C, Zuckerman JD, Nordin M. Perioperating nurses and technicians' perceptions of ergonomic risk factors in the surgical environment. Applied ergonomics. 2009;40(5):833-9.

13. Keogh A, Tully MA, Matthews J, Hurley DA. A review of behaviour change theories and techniques used in group based self-management programmes for chronic low back pain and arthritis. Manual therapy. 2015;20(6):727-35.

14. Green L, Kreuter M. Health program planning: an educational and ecological approach. 4 th edn New York. NY: McGraw-Hill. 2005.

15. Glanz K, Rimer BK, Viswanath K. Health behavior: Theory, research, and practice: John Wiley \& Sons; 2015. 
16. Seifert CM, Chapman LS, Hart JK, Perez P. Enhancing intrinsic motivation in health promotion and wellness. American Journal of Health Promotion. 2012;26(3):1-12.

17. Pender NJ. Health promotion model manual. 2011.

18. Tosunoz IK, Oztunc G. Low Back Pain in Nurses. International Journal of Caring Sciences. 2017;10(3):1728.

19. Pinar R. Work-related musculoskeletal disorders in Turkish hospital nurses. Turkiye Klinikleri Journal of Medical Sciences. 2010;30(6):1869-75.

20. Ovayolu O, Ovayolu N, Genc M, Col-Araz N. Frequency and severity of low back pain in nurses working in intensive care units and influential factors. Pakistan journal of medical sciences. 2014;30(1):70.

21. El-Soud AMA, El-Najjar AR, El-Fattah NA, Hassan AA. Prevalence of low back pain in working nurses in Zagazig University Hospitals: an epidemiological study. Egyptian Rheumatology and Rehabilitation. 2014;41(3):109.

22. Kazemi SS, Tavafian SS, Hidarnia A, Montazeri A. Consequences and factors affecting work-related Iow back pain among nursing professionals: A qualitative study. Journal of the Iranian Institute for Health Sciences Research (Payesh). 2019;18(3):291-303.

23. Gielen AC, McDonald EM, Gary TL, Bone LR. Using the precede-proceed model to apply health behavior theories. Health behavior and health education: Theory, research, and practice. 2008;4:40729.

24. Green L, Ottoson J. Public Health Education and Health Promotion. Novick, L.; Morrow, C.; Mays, G., editors. Boston: Jones \& Bartlett Publishers; 2008.

25. Schulz KF, Altman DG, Moher D. CONSORT 2010 statement: updated guidelines for reporting parallel group randomized trials. Annals of internal medicine. 2010;152(11):726-32.

26. Altman DG, Schulz KF, Moher D, Egger M, Davidoff F, Elbourne D, et al. The revised CONSORT statement for reporting randomized trials: explanation and elaboration. Annals of internal medicine. 2001;134(8):663-94.

27. Kazemi SS, Tavafian SS, Hidarnia A, Montazeri A. Development and validation of the Occupational Back Pain Prevention Behaviors Questionnaire in nursing personnel. Journal of Advanced Nursing. 2019; Under Review.

28. Pakbaz M, Hosseini M, Dalvandi A. The Effect of Lumbar care (based on Back School program) on Nursing Staffs' low back pain. Iranian Journal of Rehabilitation Research. 2016;2(3):1-8.

29. Ashton LM, Morgan PJ, Hutchesson MJ, Rollo ME, Collins CE. Feasibility and preliminary efficacy of the 'HEYMAN'healthy lifestyle program for young men: a pilot randomised controlled trial. Nutrition journal. 2017;16(1):2.

30. Kattelmann KK, Bredbenner CB, White AA, Greene GW, Hoerr SL, Kidd T, et al. The effects of Young Adults Eating and Active for Health (YEAH): a theory-based Web-delivered intervention. Journal of nutrition education and behavior. 2014;46(6):S27-S41. 
31. Whatnall M, Patterson A, Hutchesson M. A brief web-based nutrition intervention for young adult university students: Development and evaluation protocol using the precede-proceed model. JMIR research protocols. 2019;8(3):e11992.

32. Calano BJD, Cacal MJB, Cal CB, Calletor KP, Guce FICC, Bongar MVV, et al. Effectiveness of a community-based health programme on the blood pressure control, adherence and knowledge of adults with hypertension: A PRECEDE-PROCEED model approach. Journal of clinical nursing. 2019;28(9-10):1879-88.

33. Gabriel EH, McCann RS, Hoch MC. Use of social or behavioral theories in exercise-related injury prevention program research: a systematic review. Sports medicine. 2019:1-14.

34. Steinmetz H, Knappstein M, Ajzen I, Schmidt P, Kabst R. How effective are behavior change interventions based on the theory of planned behavior? Zeitschrift für Psychologie. 2016.

35. Azar FE, Solhi M, Darabi F, Rohban A, Abolfathi M, Nejhaddadgar N. Effect of educational intervention based on PRECEDE-PROCEED model combined with self-management theory on selfcare behaviors in type 2 diabetic patients. Diabetes \& Metabolic Syndrome: Clinical Research \& Reviews. 2018;12(6):1075-8.

36. Ross A, Bevans M, Brooks AT, Gibbons S, Wallen GR. Nurses and health-promoting behaviors: Knowledge may not translate into self-care. AORN journal. 2017;105(3):267-75.

37. Janssens B, Vanobbergen J, Lambert M, Schols J, De Visschere L. Effect of an oral healthcare programme on care staff knowledge and attitude regarding oral health: a non-randomised intervention trial. Clinical oral investigations. 2018;22(1):281-92.

38. Hadlaczky G, Hökby S, Mkrtchian A, Carli V, Wasserman D. Mental Health First Aid is an effective public health intervention for improving knowledge, attitudes, and behaviour: A meta-analysis. International Review of Psychiatry. 2014;26(4):467-75.

39. Mahramus T, Penoyer DA, Frewin S, Chamberlain L, Wilson D, Sole ML. Assessment of an educational intervention on nurses' knowledge and retention of heart failure self-care principles and the Teach Back method. Heart \& Lung: The Journal of Acute and Critical Care. 2014;43(3):204-12.

40. de Melo Ghisi GL, Abdallah F, Grace SL, Thomas S, Oh P. A systematic review of patient education in cardiac patients: do they increase knowledge and promote health behavior change? Patient education and counseling. 2014;95(2):160-74.

41. Schreiber JA, Cantrell D, Moe KA, Hench J, McKinney E, Lewis CP, et al. Improving knowledge, assessment, and attitudes related to pain management: Evaluation of an intervention. Pain management nursing. 2014;15(2):474-81.

42. Sayakhot P, Carolan-Olah M, Steele C. Use of a web-based educational intervention to improve knowledge of healthy diet and lifestyle in women with gestational diabetes mellitus compared to standard clinic-based education. BMC pregnancy and childbirth. 2016;16(1):208.

43. Marsh-Tootle WL, McGwin G, Kohler CL, Kristofco RE, Datla RV, Wall TC. Efficacy of a web-based intervention to improve and sustain knowledge and screening for amblyopia in primary care settings. Investigative ophthalmology \& visual science. 2011;52(10):7160-7. 
44. McNamara MC, Harmon DC, Saunders J. Effect of education on knowledge, skills and attitudes around pain. British Journal of Nursing. 2012;21(16):958-64.

45. Schaller A, Petrowski K, Pfoertner T-K, Froboese I. Effectiveness of a theory-based multicomponent intervention (Movement Coaching) on the promotion of total and domain-specific physical activity: a randomised controlled trial in low back pain patients. BMC musculoskeletal disorders. 2017;18(1):431.

46. George LE, Locasto LW, Pyo KA, Cline TW. Effect of the dedicated education unit on nursing student self-efficacy: A quasi-experimental research study. Nurse education in practice. 2017;23:48-53.

47. Thompson R, George LE. Preparing new nurses to address bullying: The effect of an online educational module on learner self-efficacy. Medsurg Nursing. 2016;25(6):412.

48. Fida R, Laschinger HKS, Leiter MP. The protective role of self-efficacy against workplace incivility and burnout in nursing: A time-lagged study. Health care management review. 2018;43(1):21-9.

49. Bandura A. Self-efficacy: The exercise of control: Macmillan; 1997.

50. Bandura A. The explanatory and predictive scope of self-efficacy theory. Journal of social and clinical psychology. 1986;4(3):359-73.

51. Bandura A. Self-efficacy: toward a unifying theory of behavioral change. Psychological review. 1977;84(2):191.

52. Perry EV, Francis AJ. Self-efficacy, pain-related fear, and disability in a heterogeneous pain sample. Pain Management Nursing. 2013;14(4):e124-e34.

53. Sheeran P, Maki A, Montanaro E, Avishai-Yitshak A, Bryan A, Klein WM, et al. The impact of changing attitudes, norms, and self-efficacy on health-related intentions and behavior: a meta-analysis. Health Psychology. 2016;35(11):1178.

54. Wu SFV, Courtney M, Edwards H, McDowell J, Shortridge-Baggett LM, Chang PJ. Self-efficacy, outcome expectations and self-care behaviour in people with type 2 diabetes in Taiwan. Journal of clinical nursing. 2007;16(11c):250-7.

55. Irvine AB, Russell H, Manocchia M, Mino DE, Glassen TC, Morgan R, et al. Mobile-Web app to selfmanage low back pain: randomized controlled trial. Journal of medical Internet research. 2015;17(1):e1.

56. Jacobs ZG, Elnicki DM, Perera S, Weiner DK. An E-learning Module on Chronic Low Back Pain in Older Adults: Effect on Medical Resident Attitudes, Confidence, Knowledge, and Clinical Skills. Pain Medicine. 2018;19(6):1112-20.

57. Maghbouli R, Kazemi S-S, Jamshidi AR. The effect of an educational Intervention on low back pain preventive behavior among nursing students: A pre-posted designed study. International Journal of Musculoskeletal Pain Prevention. 2018;3(4):102-6.

58. Merolli M, Gray K, Martín-Sánchez F, Schulz P, editors. Expert insights on the design and implementation of interactive patient websites for people with chronic pain. HIC; 2014. 


\section{Tables}

Table 1: The demographic description of the participants in groups separately

\begin{tabular}{lll}
\hline & In-person $(\mathrm{n}=60)$ & Social media $(\mathrm{n}=60)$ \\
\hline Age, years (Mean \pm SD) & $36 \pm 5.84$ & $37 \pm 5.74$ \\
Height, cm(Mean \pm SD) & $161.77 \pm 6.64$ & $162.10 \pm 6.77$ \\
Weight, kg (Mean \pm SD) & $65.92 \pm 11.70$ & $66.25 \pm 11.70$ \\
BMI (Mean \pm SD) & $25.09 \pm 3.36$ & $25.07 \pm 3.09$ \\
Work Experience, years (Mean \pm SD) & $12.08 \pm 5.91$ & $12.23 \pm 5.00$ \\
Work Hours (Mean \pm SD) & $48.45 \pm 8.14$ & $49.90 \pm 19.38$ \\
Education Level (\%) & & $1(1.7)$ \\
Associate & $2(3.3)$ & $53(88.3)$ \\
Bachelor & $51(85)$ & $6(10)$ \\
Master & $7(11.7)$ & \\
\hline
\end{tabular}

Table 2: Median scores of in-person and social media intervention groups at baseline

* Mann-Whitney U Test. All others by T-Test

\begin{tabular}{llllll}
\hline & \multicolumn{2}{l}{ In-person group } & \multicolumn{3}{l}{ Social media group } \\
& Median & IQ range & Median & IQ range & $\mathrm{p}^{*}$ \\
\hline Knowledge* & 50 & $50-75$ & 50 & $50-75$ & .98 \\
Attitude* & 55 & $50-63.75$ & 55 & $50-60$ & .54 \\
Self-efficacy* & 50 & $41.67-62.50$ & 52.08 & $45.83-62.50$ & .98 \\
Reinforcing factor & 55 & $40-65$ & 50 & $40-65$ & .90 \\
Enabling factor & 42.86 & $32.14-57.14$ & 44.64 & $32.14-57.14$ & .89 \\
Behaviour* & 50 & $33.33-58.33$ & 50 & $33.33-58.33$ & .92 \\
\hline
\end{tabular}


Table 3: Mean scores of in-person and social media intervention groups across the three time periods (mean \pm standard deviation)

\begin{tabular}{lllllll}
\hline \multicolumn{2}{c}{ In-person group } & \multicolumn{5}{l}{ Social media group } \\
\hline & Baseline & 3-month & 6 -month & Baseline & 3-month & 6-month \\
\hline ledge & $56.25 \pm 22.37$ & $90 \pm 13.96$ & $80.83 \pm 15.51$ & $56.67 \pm 23.85$ & $93.33 \pm 12.06$ & $93.75 \pm 1091$ \\
de & $54.75 \pm 8.1$ & $84.92 \pm 11.4$ & $84.50 \pm 11.33$ & $55.08 \pm 7.45$ & $86.50 \pm 10.3$ & $86.33 \pm 9.64$ \\
fficacy & $52.71 \pm 13.65$ & $60.56 \pm 13.23$ & $59.86 \pm 12.92$ & $52.22 \pm 13.56$ & $65.90 \pm 13.32$ & $67.36 \pm 15.85$ \\
jrcing factor & $53.67 \pm 16.46$ & $60.67 \pm 14.30$ & $60.25 \pm 15.33$ & $53.33 \pm 15.34$ & $62.25 \pm 16.96$ & $66 \pm 16.84$ \\
ing factor & $45.24 \pm 17.44$ & $47.20 \pm 15.33$ & $50 \pm 11.65$ & $44.82 \pm 16.51$ & $51.85 \pm 14.18$ & $53.45 \pm 9.64$ \\
iour & $49.58 \pm 19.31$ & $57.78 \pm 14.38$ & $59.31 \pm 8.55$ & $49.31 \pm 19.12$ & $62.92 \pm 12.69$ & $71.53 \pm 6.38$ \\
\hline
\end{tabular}

Table 4: The variables statistics test change scores for the in-person and social media intervention across the three time periods (mean \pm standard deviation)

\begin{tabular}{llccccc}
\hline & \multicolumn{2}{c}{ (Baseline and 3-month follow-up) } & (3-month and 6-month follow-up) & \multirow{2}{*}{ P* $^{*}$ Eta } \\
\cline { 2 - 5 } & In-person & Social media & In-person & Social media & & \\
\hline swledge & $33.75 \pm 24.27$ & $36.66 \pm 25.40$ & $-9.17 \pm 19.51$ & $.42 \pm 16.90$ & .01 & .050 \\
tude & $30.16 \pm 14.02$ & $31.41 \pm 12.38$ & $-.41 \pm 15.19$ & $-.16 \pm 16.07$ & .52 & .003 \\
f-efficacy & $7.84 \pm 20.96$ & $13.68 \pm 20.61$ & $-.69 \pm 18.12$ & $1.46 \pm 21.57$ & .03 & .039 \\
nforcing factor & $7.00 \pm 21.43$ & $8.91 \pm 21.59$ & $-.41 \pm 21.84$ & $6.33 \pm 21.64$ & .05 & .032 \\
Lbling factor & $1.96 \pm 25.91$ & $7.02 \pm 23.32$ & $2.79 \pm 17.84$ & $1.61 \pm 16.78$ & .30 & .009 \\
laviour & $8.20 \pm 25.04$ & $13.61 \pm 23.26$ & $1.53 \pm 14.59$ & $8.61 \pm 13.37$ & .001 & .095 \\
\hline
\end{tabular}

* Based on mixed between-within subject analysis of variance

\section{Figures}




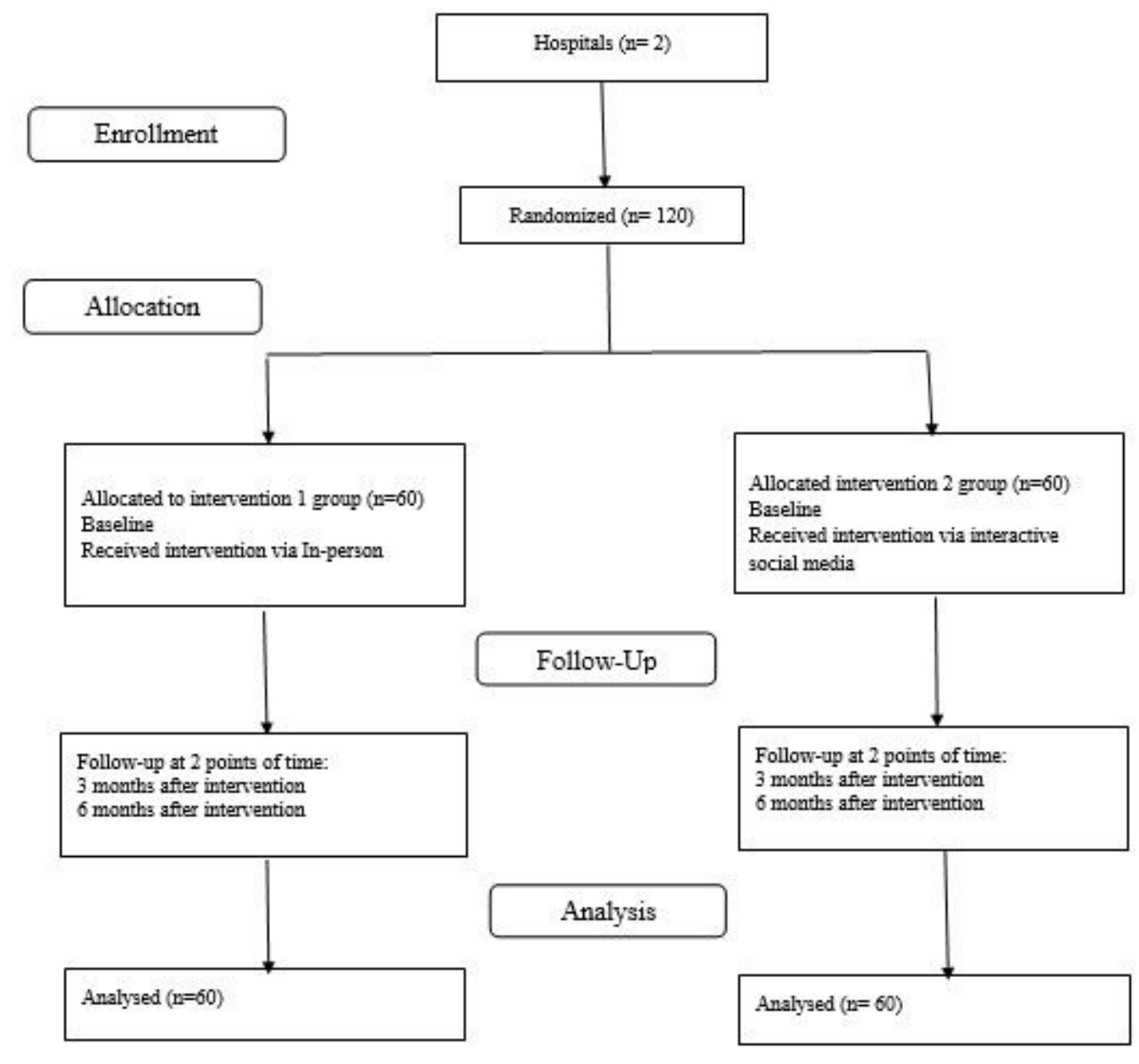

Figure 1

Flowchart and overview of the trial 


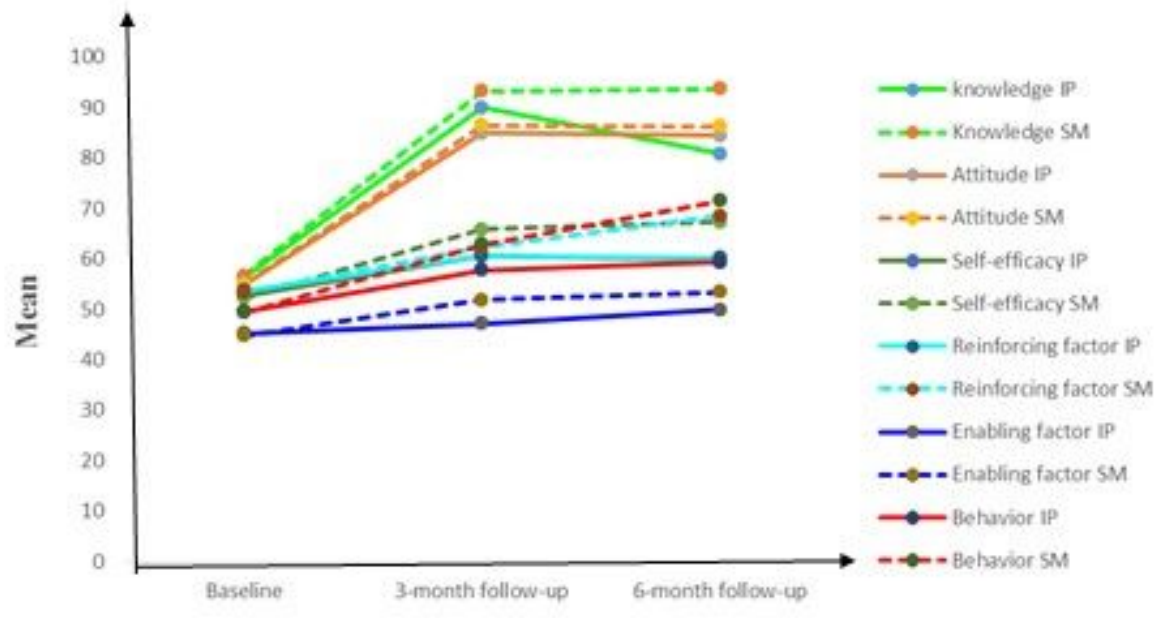

Figure 2

In-person and social media intervention across three time periods IP: In-person group SM: Social Media group

\section{Supplementary Files}

This is a list of supplementary files associated with this preprint. Click to download.

- SSK.SPSS.sav

- CONSORT2010Checklist.doc 